\title{
Reducing Efficiencies of the Commonly Used Heat Treatment Methods and Fermentation Processes on Aflatoxin M1 in Naturally Contaminated Fresh Cow Milk
}

\author{
G. K. Omeiza1, M. Mwanza², S. I. Enem1, E. Godwin'1, M. A. Adeiza1', C. Okoli ${ }^{1}$ \\ ${ }^{1}$ Department of Veterinary Public Health and Preventive Medicine, Faculty of Veterinary Medicine, University of Abuja, \\ Abuja, Nigeria \\ ${ }^{2}$ Department of Animal Health, Faculty of Natural and Agricultural Sciences, Mafikeng Campus, North West University, \\ Mmabatho, South Africa \\ Email: ojvm@sciresp.org
}

How to cite this paper: Omeiza, G.K., Mwanza, M., Enem, S.I., Godwin, E., Adeiza, M.A. and Okoli, C. (2018) Reducing Efficiencies of the Commonly Used Heat Treatment Methods and Fermentation Processes on Aflatoxin M1 in Naturally Contaminated Fresh Cow Milk. Open Journal of Veterinary Medicine, 8, 134-145. https://doi.org/10.4236/ojvm.2018.88013

Received: June 13, 2018

Accepted: August 28, 2018

Published: August 31, 2018

Copyright $\odot 2018$ by authors and Scientific Research Publishing Inc. This work is licensed under the Creative Commons Attribution International License (CC BY 4.0).

http://creativecommons.org/licenses/by/4.0/ (c) (i) Open Access

\begin{abstract}
The reducing efficiencies of the commonly used heat treatment methods and fermentation processes on aflatoxin M1 (AFM1) in Nigeria were investigated. Seventy samples of fresh cow milk from both conventional and traditional dairy cattle herds were collected and analyzed for the determination of AFM1 using Cobra-cell incorporated high performance liquid chromatography. Of these analyzed samples, $56(80.0 \%)$ tested positive for AFM1 out of which 3 milk samples with high AFM1 concentrations were selectively pooled and subjected to varied conditions of heat treatments and fermentation processes using both indigenized and exotic strains of lactic acid bacteria (Lactobacillus bulgaricus + Streptococcus thermophilus and L. rhamnosus and L. plantarum) as starter cultures respectively. Both processes used either singly or combined, demonstrated high degrees of reducing effects on AFM1 levels. Sterilization of the milk at $121^{\circ} \mathrm{C}$ and $80^{\circ} \mathrm{C}$ under the same condition of time $(15-20)$ min showed significant reduction of up to $58.8 \%(\mathrm{p}<0.05)$ when compared with the fresh untreated cow milk of the same source. Application of heat treatments within the acceptable pasteurization conditions of $61^{\circ} \mathrm{C}$ for $15-20$ min showed no significant reduction $(p>0.05)$ in the level of AFM1 when compared with the initial mean AFM1 concentration of the untreated fresh milk. The situation was however different around the boiling temperature of $100^{\circ} \mathrm{C}$ at which point the level of AFM1 reduction was found to be inconsistent. The indigenized combined strains showed some slight margins of AFM1 reduction in the proportions of $(20.5,30.8$ and 43.9$) \%$ over and above that of the exotic strains $(17.4,30.0$ and 41.1$) \%$ in $12 \mathrm{~h}, 48 \mathrm{~h}$ and $72 \mathrm{~h}$
\end{abstract}


of fermentation respectively. Generally, fermentation alone showed lower reduction of AFM1 in milk from $24.5 \%$ to $43.9 \%$ compared with the reducing activities of (35.4 to 58.8 )\% when heat-treated milk samples were subsequently subjected to varied fermentation conditions.

\section{Keywords}

Fresh Milk, Aflatoxin M1, Heat Treatment, Fermentation Processes, Nigeria

\section{Introduction}

Aflatoxins M1 (AFM1) is the principal hydroxylated metabolite of aflatoxin B1 (AFB1). AFB1 is the major secondary metabolite produced by Aspergillus species specifically Aspergillus flavus. AFM1 was once classified as group 2B carcinogen to humans by the International Agency for Research on Cancer [1]. Today, such classification is considered erroneous as further investigation demonstrated its in vivo genotoxicity and cytotoxicity effects [2]. AFM1 has been reclassified as a group 1 human carcinogen [3]. AFM1 is excreted through milk produced by lactating animals that have ingested contaminated feeds with AFB1. The recovery of AFM1 from ingested AFB1 is variable depending on the ingested concentration and the animal and it ranges between 1\% - 3\% [4]. AFB1 in the proportion of $0.3 \%-6.2 \%$ was also estimated to be transformed to AFM1 in milk [5].

The USFDA puts the action levels for AFB1 and AFM1 as $5 \mathrm{ppb}$ and $0.5 \mathrm{ppb}$ respectively in dairy products; it implies that the potency of AFM1 is one tenth that of AFB1. In spite of this marked difference in the action levels, AFM1 still represents a potential carcinogen for humans [6]. The contamination of dairy products with AFM1 is considered a significant human health hazard, particularly for children in their early stage of life, which depend wholly on milk for survival. The tolerance limit for AFM1 in milk varies from one country to the other. The European Union (EU) and Codex Alimantarius Commission put an action level for AFM1 in liquid milk at $50 \mathrm{ng} / \mathrm{L}$ whereas the USFDA operates a more relaxed safety level of $500 \mathrm{ng} / \mathrm{L}$ [7].

Aflatoxin is a troublesome milk contaminant, in this paper; the authors have evaluated the heat treatment methods and fermentation processes to remove aflatoxin M1. Reports abound which support the heat stability of AFM1 in raw and processed milk products during pasteurization and processing [8] [9] [10]. Such reports were findings emanating mostly from experiments bordering around spiked food substances. Effects of heat treatments and fermentation processes using the indigenized probiotic strains as starter cultures on the naturally AFM1 contaminated dairy products have not been fully exploited. More so, in Nigeria, there may be in existence but weak policies which aim at monitoring the aflatoxin burdens of the dairy products marketed for human consumptions. This is even worse considering the traditionally processed dairy products which 
complement the greater deficits of dairy products among the few conventional dairy farms. More so, increased demands for dairy products due to exponential increases in the Nigerian population growth have encouraged compromise in the standardization of processed dairy products. Therefore, undertaking a study to evaluate the reducing effects of the commonly used treatment methods of milk by the local handlers particularly in situations where monitoring policies which enforce the set limits for AFM1 in dairy products are not fully enforced, may be beneficial in the management of the local aflatoxin burden of cow milk in Nigeria.

\section{Materials and Methods}

\subsection{Study Site}

The study was conducted in Kaduna State of Nigeria. Kaduna state is located at the centre of Northern Nigeria between latitude $5^{\circ} 19^{\prime} 60^{\prime \prime} \mathrm{N}$ and longitude $7^{\circ} 45^{\prime} 0$ " $\mathrm{E}$ in the north central geographical zone of Nigeria [11]. The state has accessible links with many parts of the country giving room for interstate and international trades. By virtue of this location, the state enjoins trans-cultural co-existence and is advantageously positioned as part of the few states which form the economic hub of the country. Its land mass covers a total land area of 46,053 square kilometres. The 2006 population put population figure of the state at 6,006,562. This gives the state a population density of about $130 / \mathrm{km}^{2}$ (340/sq mi). The state has a reasonable economic impact with gross domestic product (GDP) of $\$ 5.33$ billion in 2007, with per capital income of $\$ 1666$. Agriculture is the main stay of the economy of Kaduna state with about $80 \%$ of the people actively engaged in livestock and crop farming. The livestock reared include cattle, sheep, goats and pigs [12].

\subsection{Sample Collection and Processing}

A total of 70 samples of fresh raw milk were collected randomly from 3 conventional dairy farms and 2 traditional Fulani dairy herds within a period of 7 weeks. Milk collection began by cleaning the udder of the selected cows with clean disposable hand towels. Hand milking was adopted for the extraction of about $50 \mathrm{ml}$ of milk from the mammary glands of the selected cows into a $50 \mathrm{ml}$ capacity sample bottle under a firm restraint technique of the affected animal by the animal attendant. Two samples were collected weekly from each farm and at the end, about 7 sets of samples were collected.

\subsection{Determination of AFM1 Concentrations}

\subsubsection{AFM1 Clean-up Procedure Using IAC}

Sample extracts were cleaned using "VICAM" method. Five gram of fresh milk sample was mixed with $1 \mathrm{~g}$ of salt $(\mathrm{NaCl})$ and placed in a blender jar. To the sample was added $20 \mathrm{ml}$ of methanol-water $(80 / 20 \mathrm{v} / \mathrm{v})$ and the mixture blended for $5 \mathrm{~min}$. The mixture was filtered through fluted filtered paper in a clean vessel. 
From the filterate, $2 \mathrm{ml}$ was collected and diluted to $5 \mathrm{ml}$ with purified water and then filtered through a glass microfiber filter. From the filterate, $2 \mathrm{ml}$ was collected and passed through IAC after which the column was washed successively with $5 \mathrm{ml}$ of purified water. AFM1 was eluted with $1 \mathrm{ml}$ of methanol and collected in a glass cuvette. The extract was finally dried under nitrogen stream and stored at $-20^{\circ} \mathrm{C}$ till HPLC analysis.

\subsubsection{High Performance Liquid Chromatographic Determination of Aflatoxin M1}

The Shimadzu Prominence UFLC Liquid chromatography system (Kyoto, Japan) was used for the HPLC determination. It consists of a Liquid Chromatography, LC-20AD which is fitted to a degasser, DGU $20 \mathrm{~A}_{5 \mathrm{R}}$, auto sampler (injection) SIL 20A, communication bus module CBM 20A, column oven CTO 20A, photodiode array detector SPD M20A and fluorescent detector RF 20A XL, connected to a gigabyte computer with Intel Core DUO and Microsoft XP operating system. The analytes that fluorescence were detected at specific excitation and emission wavelengths also referred to as the compound's fluorescence signature. Extracts from IAC were dissolved in $500 \mu \mathrm{l}$ of HPLC grade acetonitrile. Samples were run at a flow-rate of $1 \mathrm{ml}$ per minute $\left(\mathrm{min}^{-1}\right)$ retention times. Aflatoxin analysis involved the coupling to the detector of a coring cell (CoBrA cell) (Dr Weber Consulting, Germany) as an electrochemical cell for the derivatisation of aflatoxins. The following mobile phases were used for the analysis of Aflatoxins-Methanol/Acetonitrile/Water (20/20/60, v/v/v) containing $119 \mathrm{mg}$ of potassium bromide $(\mathrm{KBr})$ and $350 \mathrm{ul}$ of nitric acid $\left(4 \mathrm{M} \mathrm{HNO}_{3}\right)$.

\subsubsection{Aflatoxin M1 Analysis of the Test Samples}

The Shimadzu Prominence UFLC Liquid chromatography system (Kyoto, Japan) was used for the determination of AFM1. The HPLC was fitted to photodiode array detector SPD M20A and fluorescent detector RF 20A XL with a detection limit of $0.0125 \mathrm{ng} / \mathrm{l}$ and recovery rate of $92 \%$ for milk. Aflatoxin analysis involved the coupling to the detector a coring cell (CoBrA cell) (Dr Weber Consulting, Germany) as an electrochemical cell for the derivatization of aflatoxins. Spiked concentrations of AFM1 were prepared in triplicates with concentrations of 75, 150 and $300 \mathrm{ng} / \mathrm{l}$ of AFM1 standards, mixed thoroughly and extracted. The calculated area under the curve for the standards is entered in a system of coordinates on a semi-logarithmic graph paper against the AFM1 concentration in $\mathrm{ng} / \mathrm{l}$. Then the concentration of AFM1 corresponding to the area of each sample was read and determined from the calibration curve using the formula, $y=2460.6 \mathrm{x}$ as shown in Figure 1 .

\subsection{Aflatoxin M1 Reduction Design}

The heat-treatment and fermentation experiments were presented as $(2 \times 4)$ and $(2 \times 3)$ factorial designs respectively. The AFM1 reduction experiment employed different heat treatment methods and fermentation processes using different 


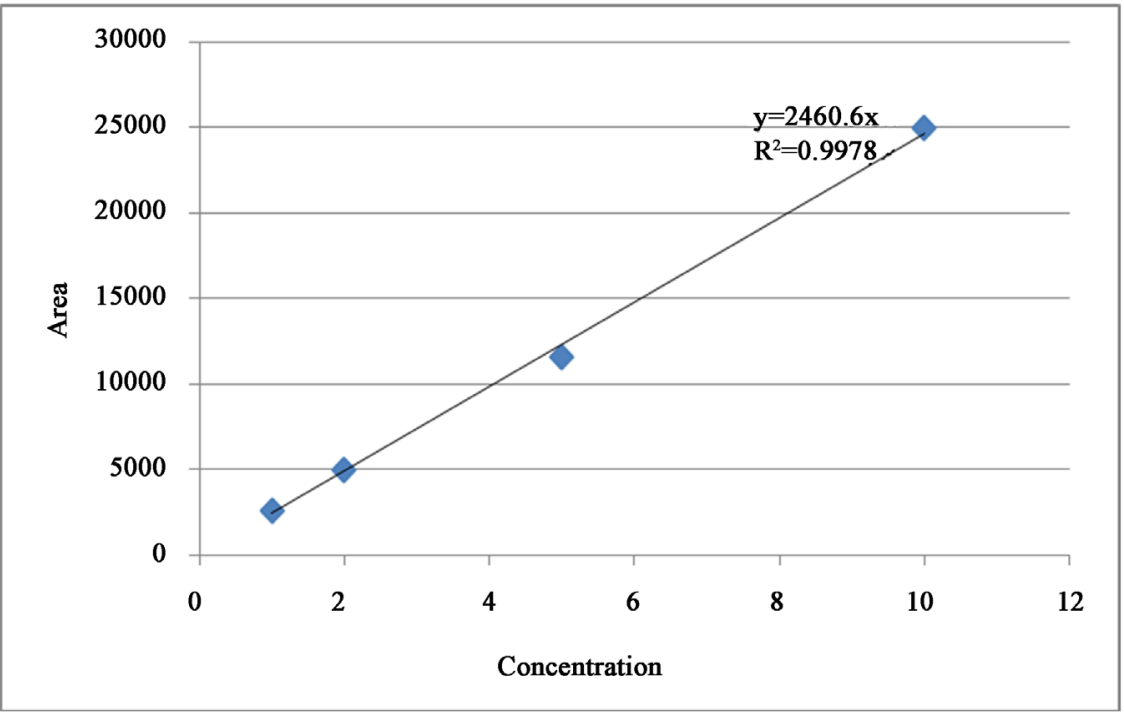

Figure 1. Calibration curve for AFM1.

lactic acid bacterial (LAB) starter cultures. Phosphate buffer saline suspension of the AFM1 extract of the naturally contaminated milk sample was used as the positive control while the extract of the uncontaminated fresh milk suspended in PBS was used as the negative control. Sixteen (M1-M16) equal portions of $5 \mathrm{ml}$ of AFM1 positive milk samples were used in the reduction experiments.

\subsection{Methods of Reducing AFM1}

\subsubsection{Heat Treatment of Milk}

1) Reduction of AFM1 through Controlled heat treatment of milk

Three milk samples with considerable detectable levels of AFM1 were randomly selected amongst others for the experiment. The 3 samples were pooled to obtain a minimal sample size of $80 \mathrm{ml}$ with AFM1 mean concentration of $0.24 \pm$ $0.05 \mathrm{ng} \cdot \mathrm{L}^{-1}$. The pooled sample was divided into 16 portions of $5 \mathrm{ml}$ each in test tubes by means of sterile pipettes. Then 6 portions (M1-M6) were used for this part of the experiment while (M7-M16) were utilized for other experiments as described below. The M1 (5.0 ml) represents the control (no heat treatment), M2 $(5.0 \mathrm{ml})$ represents heat treatment at $61^{\circ} \mathrm{C}$ for $15 \mathrm{~min}, \mathrm{M} 3(5.0 \mathrm{ml})$ represents heat treatment at $61^{\circ} \mathrm{C}$ for $20 \mathrm{~min}, \mathrm{M} 4(5.0 \mathrm{ml})$ represents heat treatment at $80^{\circ} \mathrm{C}$ for $20 \mathrm{~min}, \mathrm{M} 5(5.0 \mathrm{ml})$ represents boiling of milk at $100^{\circ} \mathrm{C}$ for $20 \mathrm{~min}$, and M6 (5.0 ml) represents milk sterilization at $121^{\circ} \mathrm{C}$ for $15 \mathrm{~min}$. Samples M2-M6 were arranged individually in metal racks. Each sample except M1 and M6, was heated in a water bath tempered at each given temperature. But sample M6 was autoclaved while M1 was left as a positive control. All treated samples were immediately cooled before further analysis.

2) Reduction of AFM1 through unregulated heat treatment of milk

One portion, sample M7 $(5.0 \mathrm{ml})$ of the pooled fresh milk was subjected to uncontrolled heat treatment. The sample in $5 \mathrm{ml}$ quantity was placed in a metal rack inside a metal case cooking pot. The arrangement was made in such a way 
that the $5 \mathrm{ml}$ sample level was just immersed in water inside the pot. The whole setting was traditionally set on fire for cooking for about $20 \mathrm{~min}$. The sample was cooled immediately before processing for HPLC analysis.

\subsubsection{Fermentation Processes}

\section{1) Preparation of lactic acid bacterial innocula}

The strains of LAB used in the study adopt modified methods of [13] [14]. The strains of the LAB were individually cultivated in a $25 \mathrm{ml}$ quantity of De-Man-Rogosa-Sharpe (MRS) broth maintained at $\mathrm{PH}$ of 6.5 and incubated in an incubator that housed an anaerobic jar containing $5 \% \mathrm{CO}_{2}$ at $37^{\circ} \mathrm{C}$ for 24 hours. Serial dilutions of the broth cultures were made to obtain three different concentrations of innocula of $\left(3 \times 10^{8}, 2 \times 10^{8}\right) \mathrm{CFUml}^{-1}$ for the single strains of Lactobacillus rhamnosus and L. plantarum respectively. An innoculum dose of a combined strain of L. bulgaricus + Streptococcus thermophilus, was however obtained by harvesting $3 \times 10^{8} \mathrm{CFUml}^{-1}$ from an MRS cultures of each of the combined strains. A loopful of each of the above LAB concentrations was suspended in $1 \mathrm{ml}$ of phosphate buffer saline (PBS).

\section{2) Reduction of AFM1 through fermentation of milk}

The $1 \mathrm{ml}$ suspension of each of the prepared innocula was directly inoculated, by the help of Eppendorf tube, into the test AFM1 contaminated milk samples.The last 9 portions (M8-M16) of $5 \mathrm{ml}$ samples of fresh milk each were utilized for the fermentation experiments under 3 different probiotic culture systems using a standardized indigenized combined strains of Lactobacillus bulgaricus + Streptococcus thermophilus obtained from a local dairy institution (LBST) and single exotic strains of L. rhamnosus (ATCC 53103) and L. plantarum (ATCC 8014) as starter cultures. Samples M8-M16 were arranged in 3 groups. Each of the groups consists of 3 test tubes of $5 \mathrm{ml}$ of fresh milk. The test samples in test-tubes were heated slowly to $85{ }^{\circ} \mathrm{C}$ and maintained at that temperature for 2 minutes. This step was designed to kill undesirable contaminant microorganisms. It also denaturizes certain inhibitory enzymes that retard the subsequent fermentation processes. The milk was then allowed to cool in a cold water bath to $42^{\circ} \mathrm{C}-44^{\circ} \mathrm{C}$. The cooling process took about 15 minutes. The starter cultures as prepared were inoculated and mixed with a clean glass rod in accordance with the method described by [14] as modified. The setting was incubated at $42^{\circ} \mathrm{C}$ and the Samples in the 3 test tubes representing different groups were monitored and examined by high performance liquid chromatography at intervals of $0 \mathrm{hr}, 12 \mathrm{hr}, 48 \mathrm{hr}$ and $72 \mathrm{hr}$.

3) Reduction by a combined heat treatment and fermentation of milk

In this section of the experiment, the test milk samples (M8 - M16) were initially subjected to pasteurization and sterilization temperatures as indicated in the early part of the methodology involving heat treatment of milk. The heat-treated milk samples were then allowed to cool in a cold water bath to about $(42-44)^{\circ} \mathrm{C}$. The heat-treated milk samples were then resubjected to fermentation processes by inoculating the prepared probiotic starter cultures at the 
prepared inoculation doses as indicated in the previous method. The inoculated milk was then incubated at $42^{\circ} \mathrm{C}$ and the levels of aflatoxin $\mathrm{M} 1$ were quantitatively determined using high performance chromatographic technique as described above.

\section{Results and Discussion}

Aflatoxin M1 (AFM1) remains a potential public health threat through the consumption of dairy products [6], particularly in the tropics where feed contaminations due to toxigenic strains of Aspergillus section flavi and their toxins may be common problems. AFM1 is the principal hydroxylated metabolite of AFB1, one of the most potent hepato-carcinogens [3] characterized mainly by its cytotoxic and genotoxic capabilities [2], produced primarily by Aspergillus flavus and $A$. parasiticus. AFM1 is found in the milk secretions of lactating animals previously exposed to contaminated feeds. In this research, 56 out of the 70 fresh cow milk samples $(80.0 \%)$ were positive for AFM1 out of which 3 samples were selectively pooled to obtain a mean AFM1 concentration of $0.24 \pm 0.05 \mathrm{ngL}^{-1}$ and was subjected to various temperature treatments and fermentation processes. Findings generally revealed that both processes showed variable degrees of reducing effects in the levels of AFM1 amongst the naturally contaminated milk samples tested. A more significant reduction of AFM1 in milk was noticed when pasteurized and sterilized milk samples were subsequently exposed to fermentation processes under different LAB starter cultures. AFM1 concentrations determined showed a statistically significant difference $(\mathrm{p}<0.05)$ between the fresh untreated cow milk and the sterilized version of the cow milk at $121^{\circ} \mathrm{C}$ and $80^{\circ} \mathrm{C}$ for $(15-20) \mathrm{min}$. Sterilization of fresh cow milk at $121^{\circ} \mathrm{C}$ achieved a significant level ( $\mathrm{p}<0.05$ ) of AFM1 reduction of up to $58.8 \%$ over the other temperature treatment conditions (Figure 2). This finding seemed good, but may otherwise negatively affect the wholesomeness of the milk. However, application of heat treatments within the acceptable pasteurization conditions of $61^{\circ} \mathrm{C}$ for $15-20 \mathrm{~min}$, showed no significant reduction $(\mathrm{P}>0.05)$ in the level of AFM1 concentration when compared with the initial mean AFM1 concentration of the untreated fresh milk sample of $0.24 \pm 0.05 \mathrm{ngL}^{-1}$ as shown in Table 1 . These findings showed some level of agreement with that of [8] which demonstrated a significant decrease in AFM1 concentration of nearly $56 \%$ reduction after subjecting spiked concentrations of AFM1 to sterilization conditions of $121^{\circ} \mathrm{C}$ for $15 \mathrm{~min}$. The findings may also be suggestive of the fact that the usual acceptable pasteurization conditions may exert non-significant reducing effect on the concentration of AFM1 in naturally contaminated fresh milk. From Table 1, also, reduction level of AFM1 somewhat depicts a direct relationship between the amount of temperature applied and the levels of reduction. The situation however seemed different around the boiling temperature of $100^{\circ} \mathrm{C}$ at which point the level of AFM1 reduction was inconsistent with the above established relationship. This temperature level may represent an equilibrium state within 


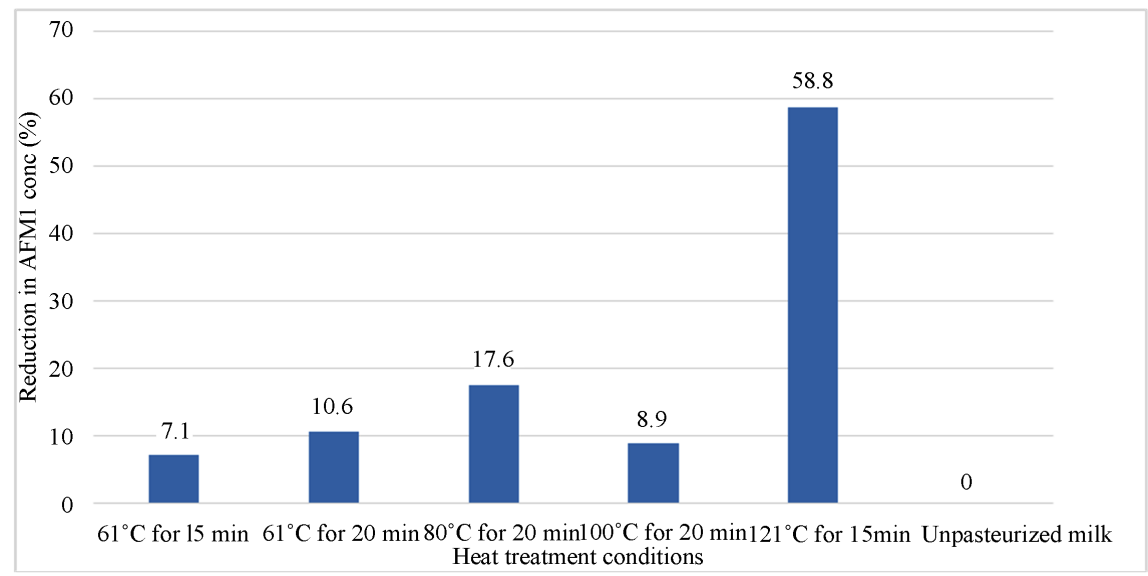

Figure 2. Reducing efficiencies of different temperature treatments on AFM1 concentration in milk.

Table 1. Heat reduction effect of a naturally occurring AFM1 in fresh cow milk.

\begin{tabular}{|c|c|c|c|c|c|c|c|}
\hline \multirow{2}{*}{$\begin{array}{c}\text { Heat } \\
\text { treatment } \\
\text { conditions }\end{array}$} & \multirow{2}{*}{$\begin{array}{c}\begin{array}{c}\text { Untreated } \\
\text { fresh milk }\end{array} \\
\text { Mean AFM1 } \\
\text { conc. of initial } \\
\text { samples (M1) }\end{array}$} & \multicolumn{5}{|c|}{$\begin{array}{l}\text { Heat-treated milk samples at different } \\
\text { temperatures and time }\end{array}$} & \multirow{2}{*}{$\begin{array}{l}\text { Uncontrolled } \\
\text { heat treatment } \\
\text { AFM1 conc. of } \\
\text { M7 }\end{array}$} \\
\hline & & $\begin{array}{l}\text { AFM1 } \\
\text { conc. of } \\
\text { M2 }\end{array}$ & $\begin{array}{c}\text { AFM1 } \\
\text { conc. of } \\
\text { M3 }\end{array}$ & $\begin{array}{l}\text { AFM1 } \\
\text { conc. of } \\
\text { M4 }\end{array}$ & $\begin{array}{l}\text { AFM1 } \\
\text { conc. of } \\
\text { M5 }\end{array}$ & $\begin{array}{c}\text { AFM1 } \\
\text { conc. of } \\
\text { M6 }\end{array}$ & \\
\hline $\begin{array}{l}\text { No heat } \\
\text { treatment }\end{array}$ & $0.24 \pm 5.2^{\mathrm{a}}$ & & & & & & \\
\hline $\begin{array}{l}61^{\circ} \mathrm{C} \text { for } 15 \\
\min \end{array}$ & - & $0.21^{\mathrm{a}}$ & & & & & \\
\hline $\begin{array}{c}61^{\circ} \mathrm{C} \text { for } 20 \\
\min \end{array}$ & - & - & $0.21^{\mathrm{a}}$ & & & & \\
\hline $\begin{array}{c}80^{\circ} \mathrm{C} \text { for } 20 \\
\min \end{array}$ & - & - & - & $0.19^{\mathrm{a}}$ & & & \\
\hline $\begin{array}{l}100^{\circ} \mathrm{C} \text { for } 20 \\
\min \end{array}$ & - & - & - & - & $0.20^{\mathrm{a}}$ & & - \\
\hline $\begin{array}{l}121^{\circ} \mathrm{C} \text { for } 15 \\
\min \end{array}$ & - & - & - & - & - & $0.13^{\mathrm{b}}$ & - \\
\hline $\begin{array}{l}\text { Uncontrolled } \\
\text { heat treatment } \\
\text { for } 20 \mathrm{~min}\end{array}$ & - & - & - & - & - & - & $0.19^{\mathrm{a}}$ \\
\hline
\end{tabular}

which reversible chemical reactions could occur. This finding may present grave public health concern as chemical rearrangements may result in the formation of even more deleterious intermediary chemical groups of serious health implications. The above findings are important in showing that heat treatment of milk, in any case, may not be the best means of removing AFM1 from dairy products.

Controlled fermentation processes using indigenized starter cultures of LAB have shown promising results in the reduction of AFM1 burden of fermented cow milk. In the current study, synergistic effects of the two indigenized LAB starter cultures comprising of Lactobacillus bulgaricus and Streptococcus thermophilus was compared with the exotic strains of L. rhamnosus and L. plantarum. It was observed that the AFM1 reducing efficiency of the indigenized 
strains of the starter culture was reasonably compared with any other starter cultures (Figure 3). The combined indigenized strains showed some slight margins of AFM1 reduction in the proportions of (20.5, 30.8 and 43.9)\% over and above that of the L. rhamnosus $(17.4,30.0$ and 41.1$) \%$ when compared with the initial AFM1 concentration level of $0.24 \pm 0.05 \mathrm{in} 12 \mathrm{~h}, 48 \mathrm{~h}$ and $72 \mathrm{~h}$ of fermentation respectively (Figure 4). Abbes et al. (2013) [15] had previously implicated L. rhamnosus to possess more ability to remove AFM1 than L. plantarum. The competitive ability of the indigenized starter culture, L. bulgaricus and Streptococcus thermophilus, therefore, points to the safety assurance of the fermentation processes of dairy products in Nigeria. The current findings showed some level of similarity with the reports of [16] and [15] even though, their works utilized spiked AFM1 concentrations, in which case reductions of up to $12 \%$ and $97 \%$ using an initial spiked AFM1 concentration of $600 \mathrm{ppb}$ were observed. Possible explanation to these reductions could be attributed to the different abilities of the probiotic cell walls to bind toxins including AFM1 in milk [13] [15].

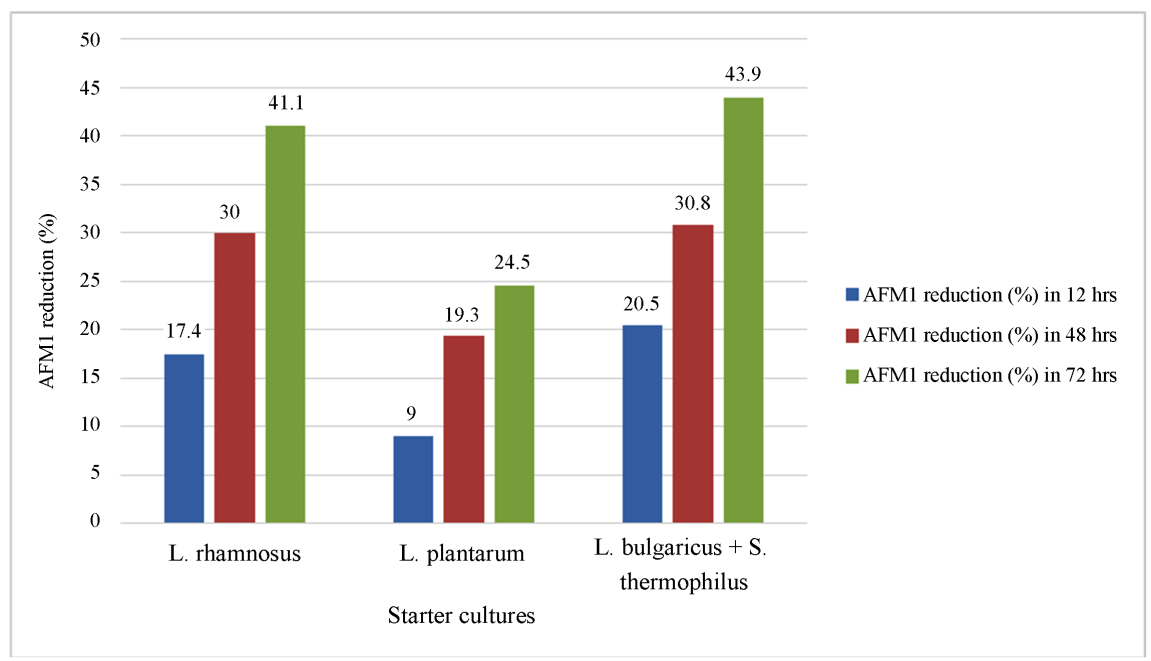

Figure 3. Comparative reducing efficiencies of different starter cultures on AFM1 concentration during fermentation processes of cow milk.

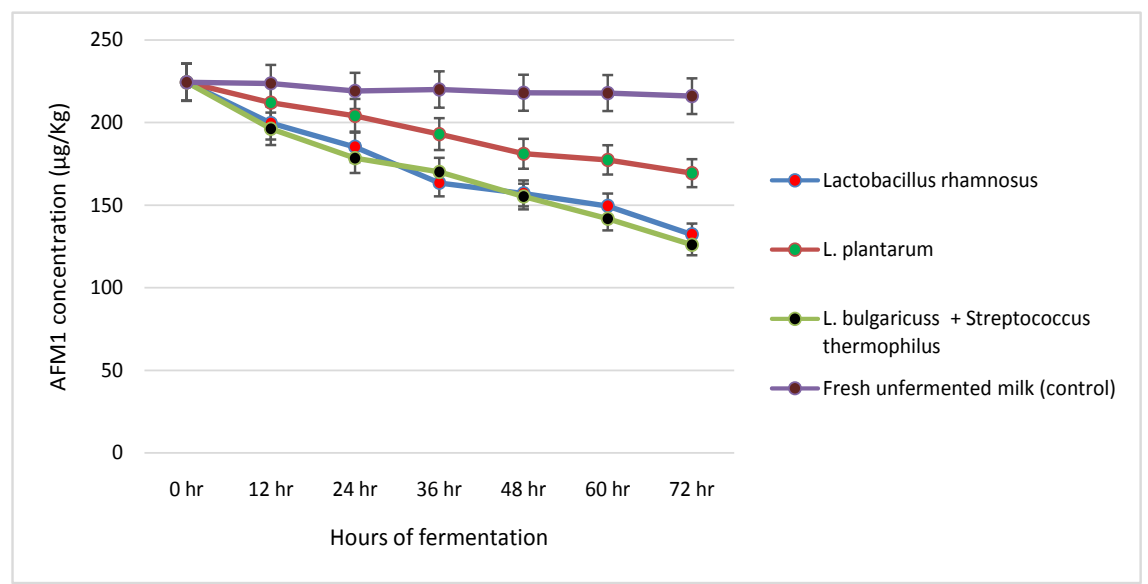

Figure 4. Effects of controlled fermentation on AFM1 concentrations. 
Table 2. Results of post-fermentation heat treatment of milk.

\begin{tabular}{|c|c|c|c|}
\hline \multirow[b]{2}{*}{$\begin{array}{l}\text { Heat treatment } \\
\text { conditions }\end{array}$} & \multicolumn{3}{|c|}{ Post-heat-treatment fermentation (AFM1 concentrations) $\left(\mu \mathrm{gL}^{-1}\right)$} \\
\hline & $\begin{array}{l}\text { AFM1 conc. of sample } \\
\text { (A) fermented using } \\
\text { Lactobacillus } \\
\text { rhamnosus (\% reduction) }\end{array}$ & $\begin{array}{l}\text { AFM1 conc. of samples } \\
\text { (B) fermented using } \\
\text { Lactobacillus plantarum } \\
\text { (\% reduction) }\end{array}$ & $\begin{array}{l}\text { AFM1 conc. of samples (C) } \\
\text { fermented using L. bulgaricus }+ \\
\text { Streptococcus thermophilus } \\
\text { (\% reduction) }\end{array}$ \\
\hline $61^{\circ} \mathrm{C}$ for $15 \mathrm{~min}$ & $0.140(41.6 \%)$ & $0.179(25.4 \%)$ & $0.132(45.0 \%)$ \\
\hline $61^{\circ} \mathrm{C}$ for $20 \mathrm{~min}$ & $0.140(41.6 \%)$ & $0.179(25.4 \%)$ & $0.132(45.0 \%)$ \\
\hline $80^{\circ} \mathrm{C}$ for $20 \mathrm{~min}$ & $0.134(44.2 \%)$ & $0.172(28.3 \%)$ & $0.122(49.2 \%)$ \\
\hline $100^{\circ} \mathrm{C}$ for $20 \mathrm{~min}$ & $0.133(44.6 \%)$ & $0.170(29.2 \%)$ & $0.123(48.8 \%)$ \\
\hline $121^{\circ} \mathrm{C}$ for $15 \mathrm{~min}$ & $0.119(50.5 \%)$ & $0.155(35.4 \%)$ & $0.099(58.8 \%)$ \\
\hline $\begin{array}{l}\text { Uncontrolled } \\
\text { heat treatment of } \\
\text { milk for } 20 \mathrm{~min}\end{array}$ & $0.130(45.8 \%)$ & $0.166(30.8 \%)$ & $0.121(49.6 \%)$ \\
\hline
\end{tabular}

AFM1 concentration of the fresh, unprocessed milk is 0.24 .

Galvano et al. (1998) [17] threw more light to this explanation that, the effect of this reduction was partly due to lactic acid formation by the lactic acid bacteria acting as an anti-AFM1 during fermentation processes.

Of interest in the study was the significant AFM1 reduction levels noticed when the pasteurized and sterilized milk samples were further subjected to fermentation processes. One way fermentation of contaminated milk only reduced the AFM1 level of contaminated milk from (24.5 to 43.9)\%, but a more significant reduction from (35.4 to 58.8)\% was however noticed when heat-treatment of milk was followed by fermentation as shown in Table 2. Previous heat treatment of milk inactivates bacterial contaminants of milk and other biological components of milk that reduce the activities of lactic acid bacterial during fermentation processes [13] [14]. So, the noticed improved reduction activities of the different fermentation cultures following heat treatment of the milk samples may not be unconnected to this fact [18]. Different bacterial cell walls may possess differed binding activities. Non-viable cells have been reported to possess greater binding efficiency or ability to AFM1 than the viable cells [13] [18]. This may be the reason behind the different reduction activities seen with the different LAB culture systems used either singly or combined.

\section{Conclusion}

Findings from this study showed that the commonly used heat treatment methods and fermentation processes in Nigeria are capable of reducing the level of contamination due to AFM1 in milk and dairy products. Elevated heat treatment temperatures and fermentation processes of cow milk demonstrated high reducing efficiencies on AFM1 burden of milk. However, reducing efficiency of heat treatment of milk exceeding a temperature of $80^{\circ} \mathrm{C}$ may present risks associated with chemical breakdown and rearrangements; with the likelihood of forming more toxic substances. However, fermentation processes used in Nigeria 
using the indigenized and combined strains of L. bulgaricus and Streptococcus thermophilus showed a promising result and therefore alludes a more credible and reliable reducing efficiency of AFM1 in milk intended for human consumption. Subsequent fermentation of heat treated milk also suggests an assured way of significantly reducing the AFM1 burden of cow milk.

\section{Acknowledgements}

The authors wish to appreciate the efforts of all those who contributed technically to this work, particularly, the technical Staff of Animal Health Department, North West University, South Africa and the Department of Veterinary Public Health and Preventive Medicine, Ahmadu Bello University, Zaria, Nigeria. We also extend our appreciation to the TETFUND through her NEEDS ASSESSMENT Programme executed by the Management of University of Abuja. The individual effort of Prof. Hussein Makun of the Department of Biochemistry, Federal University of Technology (FUT), Minna, for creating links to execute the work overseas is highly appreciated.

\section{Conflict of Interest}

There is no conflict of interest of any kind.

\section{References}

[1] International Agency for Research on Cancer (IARC) (1993) Aflatoxins. Some Naturally Occuring Substances: Food Items and Constituents, Hetrocyclic Aromatic Amines and Mycotoxins. IARC Monographs on the Evaluation of the Carcinogenic Risk to Humans. International Agency for Research on Cancer, Lyon, France, p. 56.

[2] Caloni, F., Stammati, A., Friggé, G. and De Angelis, I. (2006) Aflatoxin M1 Absorption and Cytotoxicity on Human Intestinal in Vitro Model. Toxicon, 47, 409-415. https://doi.org/10.1016/j.toxicon.2005.12.003

[3] International Agency for Research on Cancer (IARC) (2002) Some Traditional Herbal Medicines, Some Mycotoxins, Naphthalene and Styrene. Summary of Data Reported and Evaluation. IARC Monographs on the Evaluation of the Carcinogenic Risk to Humans. International Agency for Research on Cancer, Lyon, France, p. 82.

[4] Fremy, J.M., Gautier, J.P., Herry, M.P., Terrier, C. and Calet, C. (1988) Effects of Ammonization on the "Carry-Over" of Aflatoxins into Bovine Milk. Food Additives and Contaminants, 5, 39-44. https://doi.org/10.1080/02652038809373660

[5] Creppy, E.E. (2002) Update of Servey, Regulation and Toxic Effects of Mycotoxins in Europe. Toxicology Letters, 127, 19-28. https://doi.org/10.1016/S0378-4274(01)00479-9

[6] Williams, J.H., Phillips, T.D., Jolly, P.E., Stiles, J.K., Jolly, C.M. and Aggarwal, D. (2004) Human Aflatoxicosis in Developing Countries: A Review of Toxicology, Exposure, Potential Health Consequences and Interventions. American Journal of Clinical Nutrition, 80, 156-162. https://doi.org/10.1093/ajcn/80.5.1106

[7] Codex Alimentarius. Draft Maximum Level for Aflatoxin M1 in Milk, Alinorm 97/37 Report of the Twenty-Second Session of the Joint FAO/WHO Codex Alimentarius Commission, Geneva. 1997; 2001.

[8] Al-Delaimy, K.S. and Mahmoud, I.F. (2015) Aflatoxin M1 in Milk and Milk Products 
in Jordan and Methods for its Reduction: A Preliminary Study. British Journal of Applied Science \& Technology, 6, 597-605. https://doi.org/10.9734/BJAST/2015/13622

[9] Iha, M.H., Barbosa, C.B., Okada, I.A. and Trucksess, M.W. (2011) Occurrence of Aflatoxin M1 in Dairy Products in Brazil. Food Control, 22, 1971-1974. https://doi.org/10.1016/j.foodcont.2011.05.013

[10] Yousef, A.E. and Marth, E.H. (1989) Stability and Degradation of Aflatoxin M1. In: van Egmond, H.P., Ed., Mycotoxins in Dairy Products, Elsevier Applied Sciences, London, 127-161.

[11] Canback Global Income Distribution Database (C-GIDD) (2008) Canback Dangel. http://www.onlinenigeria.com/map.gif on 14/01/2015

[12] Ajala, M.K. (2004) Household Decision Making in the Production of Small Ruminants in Giwa LGA of Kaduna State of Nigeria. Proceedings of the 29th Annual Conference of the Nigerian Society of Animal Production, 399-402.

[13] Abdelmotilib, N.M., Hamad, G.M., Elderea, H.B., Salem, E.G. and El Sohaimy, S.A (2018) Aflatoxin M1 Reduction in Milk by a Novel Combination of Probiotic Bacterial and Yeast Strains. European Journal of Nutrition \& Food Safety, 8, 83-99. https://doi.org/10.9734/EJNFS/2018/39486

[14] El Khoury, A., Atoui, A. and Yaghi, J. (2011) Analysis of Aflatoxin M1 in Milk and Yogurt and AFM1 Reduction by Lactic Acid Bacteria Used in Lebanese Industry. Food Control, 22, 1695-1699. https://doi.org/10.1016/j.foodcont.2011.04.001

[15] Abbès, S., Salah-Abbès, J.B., Sharafi, H., Jebali, R., Noghabi, K.A. and Oueslati, R. (2013) Ability of Lactobacillus rhamnosus GAF01 to Remove AFM1 in Vitro and to Counteract AFM1 Immunotoxicity in Vivo. Journal of Immunotoxicology, 10, 279-286. https://doi.org/10.3109/1547691X.2012.718810

[16] Govaris, A., Roussi, V., Koidis, P.A. and Botsoglou, N.A. (2002) Distribution and Stability of Aflatoxin M1 during Production and Storage of Yoghurt. Food Additives and Contaminants, 19, 1043-1050. https://doi.org/10.1080/0265203021000007831

[17] Galvano, F., Galofaro, V., De Angelis, A., Galvano, M., Bognanno, M. and Galvano, G. (1998) Survey of the Occurrence of Aflatoxin M1 in Dairy Products Marketed in Italy. Journal of Food Protection, 61, 738-741. https://doi.org/10.4315/0362-028X-61.6.738

[18] El-Nezami, H.S., Kankaanpaa, P.E., Salminen, S. and Ahokas, J.T. (1998) Physicochemical Alterations Enhance the Ability of Dairy Strains of Lactic Acid Bacteria to Remove Aflatoxin from Contaminated Media. Journal of Food Protection, 61, 466-468. https://doi.org/10.4315/0362-028X-61.4.466 